\title{
Research on Tourism Resources and Industrial Spatial Distribution under the Construction Background of Hainan Free Trade Zone
}

\author{
Wu Xiaoliang \\ Hainan College of Economics and Business, Hainan Haikou, 571127, China
}

Keywords: tourism resources, industrial spatial distribution, Hainan Free Trade Zone

\begin{abstract}
Hainan has unique tourism resources, many of which are irreplaceable. At present, Hainan is facing a policy advantage-free trade zone. Facing the construction and development of the free trade zone, Hainan tourism industry needs to carry out rational layout and planning again in order to adapt to changes in economic environment and produce greater economic benefits. At the same time, how to combine high-quality tourism resources and advantageous policies in depth and maximize benefits is the direction that we need to work hard to develop.
\end{abstract}

\section{Introduction}

The concept of Hainan free trade zone was put forward in April 2018. It is necessary to sort out the existing advantageous industries and resources in hainan in order to build a healthy free trade zone economic system. For a long time, tourism industry has existed in Hainan as an advantageous industry. it has formed one of the important foundations of Hainan's economic development. Facing the construction and development of the free trade zone, Hainan tourism industry needs to carry out rational layout and planning again in order to adapt to changes in economic environment and produce greater economic benefits. Therefore, this paper summarizes Hainan tourism resources and makes reasonable suggestions on the spatial layout of Hainan tourism industry.

\section{Types and Distribution of Hainan Tourism Resources}

\subsection{Report of Hainan tourism resources}

According to the national standard "classification, investigation and evaluation of tourism resources” (GB / t 18972 - 2003), the national tourism resources are divided into 8 major categories, 31 subcategories and 155 basic types. According to statistics, there are about 486 tourism resources in Hainan, of which 58 are landscape in geography, 94 in waters, 34 in biology, 4 in astronomical phenomena and climate, 25 in ruins, 78 in architecture and facilities, 110 in tourism commodities and 83 in human activities, covering 8 main categories, 30 sub-categories and 135 basic types (accounting for $87 \%$ of 155 basic types in the country).

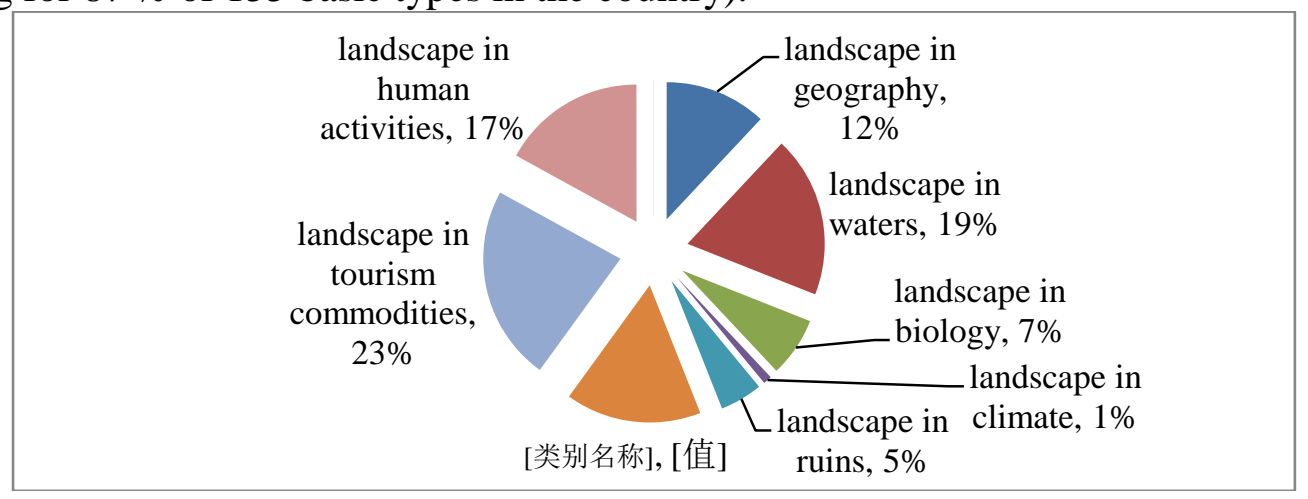

Fig. 1 Proportion of Hainan tourism resources

\subsection{Spatial distribution of Hainan tourism resources}

From a macro perspective, Hainan province has a high degree of spatial agglomeration of 
tourism resources, an obvious hierarchical structure and many resource accumulation areas. The core gathering area of forest tourism resources centered on Wuzhishan radiates from the core to its surroundings. Land mainly includes mountain, hill and coastal plain, and extends to sea areas. From the perspective of geographical form, Hainan's geographical space can be divided into mountain forest circle, platform circle, coastal circle and ocean circle. According to the distribution density of tourism resources, Hainan has formed four major cultural groups, including historical and cultural groups, western fishermen's cultural groups, eastern south China sea cultural groups and southern ethnic cultural groups. These are superimposed with the ecological circle space and constitute the combination of mountain, sea, culture and Folk custom resources. It is conducive to creating diversified tourism products, such as coastal leisure, fishermen's small towns, amorous towns, folk ancient villages, Li Miao Tribes, marine exploration, etc.

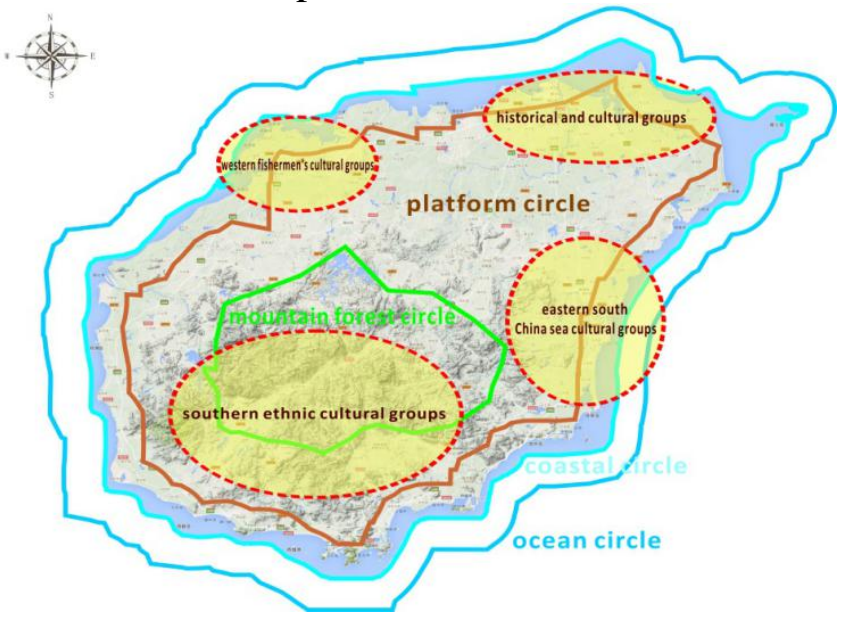

Fig. 2 Spatial distribution of Hainan tourism resources

\section{Comparative Analysis of Hainan Tourism Resources}

\subsection{Tropical ocean is Hainan's most advantageous tourist resource}

The seaside beaches of Hainan Island are white and flat. The fine daylight days of the year exceed 300 days. The visibility of seawater is 8.25 meters. Hainan has the highest quality beaches and excellent water quality in China. In addition, Hainan's Air quality for six consecutive years is first in China. Hainan has 2 million square kilometers of sea, is the largest sea area of the province and undoubtedly China's only tropical tourism island. At the same time, compared with Hawaii, Bally and other 10 famous tourist islands and coastal Tourism cities, Hainan's marine tourism resources are significantly better than Xiamen, Singapore, Jeju island and other tourist destinations. Its natural conditions are in line with Taiwan Island and International Ocean island. But its resource quality is slightly lower than that of Maldives and Bahamas.

\subsection{Tropical agriculture, tropical rainforest and hot spring tourism resources are very rich.}

Hainan is China's largest tropical crop base. Coconut, coffee, tropical fruits and other crops are rich in resources and unique. Characteristic villages, pastoral products and folk custom resources are closely combined so that the resources are of high grade and the market is attractive. But at present, Hainan's tropical product resources are not closely integrated with tourism. Therefore, the tropical agricultural manor can be carry out exquisite packaging in the future, thus enhancing tourists' tropical tourism experience.

Hainan, which has 61.9 \% forest coverage, is one of the only two tropical rainforest areas in China. Its rainforest is complex in structure, mild in climate and rich in rare species and medicinal plants, which are suitable for carrying out ecological science popularization and health preservation. Although the value of tropical rainforest is not low, its ecological value and environmental protection significance are higher. Therefore, the development and utilization intensity should be controlled, for example, the protective development should only be carried out in the peripheral test 
area.

Hainan has a complete range of water resources, including rivers, lakes, hot springs, karst caves, etc. They are closely linked to tropical climate and have a wide range of resources from cold springs to boiling springs. At the same time, they are the provinces with the highest distribution density of hot springs in China, with a large number and broad distribution. However, compared with similar resources in other provinces across the country, their uniqueness is not strong and it is difficult to become a core attraction. Therefore, they need high-quality development so as to create high-quality tourism products.

\subsection{Ethnic culture and cultural resources are another hot spot in Hainan's tourism resources}

Around the world, tourist islands are especially emphasized to attract tourists with local culture, such as Hawaii's polynesian hula dance. Phuket island is a tourist attraction with Buddhist temples and Thai customs. Bali has set up the image of "the island of thousand temples" and " the island of gods". Hainan island must also design cultural images that conform to its own characteristics. Considering the abundance and endowment of resources, Li nationality culture is a cultural resource with Hainan characteristics and has uniqueness in the world. Therefore, Li nationality culture will be the soul of Hainan's participation in the world island tourism differential competition.

In addition, Hainan is not only the "supply depot" and " transfer station" of China's maritime silk road, but also the forefront of project construction. Hainan province's maritime silk road construction in the 21st century has once again become the highlight of national attention after the " international tourism island" and the city of Sansha. As an important path to realize the Chinese dream, the construction of maritime silk road is a mission that Hainan tourism must undertake in the future and will also bring an opportunity for Hainan to develop its culture.

At the same time, fashion culture also shapes beautiful cultural images for Hainan. International conference and exhibition forums, world-class sports events, fashion talent contest and high-end life and entertainment experience have been held one after another to establish an international image of Hainan with a heart of the world, healthy, beautiful and moving, and high-end atmosphere in participating in international tourism competition.

\section{Spatial Layout Design of Hainan Tourism Industry}

\subsection{Design ideas}

According to the types and distribution of Hainan's tourism resources, under the background of the future development of Hainan's free trade zone, the overall tourism industry can be designed to the layout of "two nuclei, six zones and nine groups".

The meaning of "two cores" is Haikou tourism center city and sanya leisure resort area. In the end, Haikou and Sanya will be built into famous international tourist cities.

The six areas include the northern urban and rural tourism area, the southern vacation tourism area, the central rainforest tourism area, the eastern health tourism area, the western tourism area, and the Sansha marine tourism area.

The nine groups include Wenchang space tourism area, Qionghai exhibition and medical tourism area, Wanning marine sports tourism area, Lingshui coastal tourism area, ledong mountain and sea interactive tourism area, Danzhou volcanic coast and ancient saltworks tourism area, national park tourism area, Changhua river estuary tourism area, and Xisha islands tourism area.

\subsection{Specific development path}

\subsubsection{Two core tourist cities: Haikou and Sanya}

Haikou city - maritime silk road tourism center.Haikou city is the capital of Hainan province, which will bring a series of advantages to the development of tourism in Haikou city. First of all, the exhibition industry can get faster development. for example, Haikou exhibition center and Haikou conference center can be built, high-end service platforms for various international official and business activities can be built, the combination of exhibition center and tourism industry can 
be strengthened, and conferences and exhibitions of various sizes can be held.

Secondly, the maritime silk road culture is given to the grand historical complex of arcade street. At the same time, the construction of the maritime silk road museum will increase leisure tourism institutions such as southeast Asian style cafes, various cultural exhibition halls, galleries, antiques, etc. and the construction of an open maritime silk road cultural and leisure experience area.

Thirdly, the international cruise port will be rapidly constructed and the cruise line on the sea silk road will be developed more quickly. According to the geographical and hydrological conditions of Haikou city, over 100,000 - ton cruise ports can be built, and the cruise ring island route can be jointly developed with sanya.

Fourth, the three major international brands are mainly established. The first is the island leisure city, including: sea silk road cultural leisure, horse racing tourism leisure, ecological cultural rural leisure. The second is the capital of business meetings, including Hainan international convention and exhibition center, Haikou convention and exhibition center and Haikou convention and exhibition center. The third is the Asian golf capital, including golf world cup, world star competition, Hainan open and world women's championship. these are the top four international golf competitions.At the same time, international tourism marketing has been strengthened. Haikou will adopt differentiated marketing strategies for overseas markets.

Sanya city - the bridgehead of South China Sea tourism industry.Sanya is a well-known tourist city in China. its tourism industry has a long history. Sanya's tourism industry can be more diversified. First, sanya can build Asia's largest international cruise home port and introduce many international cruise companies to develop more attractive cruise tourism products in the South China Sea, such as the Southeast Asian route Xisha, zhongsha and Nansha routes. In addition, it can develop marine tourism and aviation entertainment projects, thus carrying out low-altitude tourism, marine air sports, aviation sightseeing and photographing and other characteristic tourism activit.

Secondly, it can optimize the atmosphere of a global tourist city, thus promoting urban integration, industrial integration, ecological integration and cultural integration. It can build a cluster of four high-end shopping, yacht tourism, high-end vacation and high-end medical services. Specifically, Sanya can try to carry out four major plans. the first proposal is to improve sanya's comprehensive tourism service function and perfect tourism service supporting facilities. these include: strengthening the construction of urban landscape and recreational facilities, controlling the disorderly expansion of the city scale, protecting limited land resources, and enriching the urban greening environment. The second suggestion is to strengthen the comprehensive coastal facilities. these include: strengthening the construction of coastal landscape, increasing tourism and vacation facilities in an orderly way, and upgrading both coastal scenic spots and coastal leisure formats. The third suggestion is to create a differentiated tourism pattern. Every different coast has different entertainment themes. The fourth suggestion is to expand marine tourism projects and create new hot spots such as sea vacations and sightseeing.

\subsubsection{Six tourist regions}

The northern urban and rural tourist area.Haikou city is the center of this area and involves Wenchang, dingan and chengmai counties. its area is 7965 square kilometers, accounting for $23.37 \%$ of Hainan island. This region focuses on the development of modern service industries and high-tech industries such as cultural entertainment, conference and exhibition, commercial catering, golf and leisure, financial insurance, education and training, real estate, etc. Tourism activities include business tourism, sports tourism, rural tourism and other entertainment projects.

The southern resort area. Sanya city is the center of this area and involves Lingshui, baoting and ledong counties. it covers an area of 6955 square kilometers, accounting for $20.41 \%$ of Hainan island. This region focuses on developing hotel accommodation, sports and entertainment, recuperation and leisure, commercial catering and other industries to give priority to creating new formats of vacation tourism and other tourism around sanya.

Central rainforest tourist area - it includes Wuzhishan, qiongzhong, tunchang and Baisha counties with an area of 7184 square kilometers, accounting for $21.07 \%$ of Hainan island. Its 
mission is to deal with the relationship between protection and development. on the basis of strengthening the protection of tropical rain forests and water sources, it will actively develop tropical characteristic agriculture, forestry economy, ecological tourism, ethnic tourism, urban service industry and ethnic handicraft manufacturing. It will develop national park tourism and $\mathrm{Li}$ and Miao cultural tourism around Wuzhishan.

Kangyang tourist area in the east - it includes Qionghai and wanning cities, covering an area of 3576 square kilometers, accounting for $10.49 \%$ of Hainan island. This region mainly develops coastal tourism, tropical agriculture, marine fishery, agricultural products processing industry, etc. at the same time, Qionghai and wanning cooperate to develop health care tourism routes and products and develop international medical tourism, coastal sports tourism and business conference tourism.

Western tourist area - it includes danzhou, lingao, Changjiang, dongfang four cities and counties and Yangpu economic development zone, with an area of 8407 square kilometers, accounting for $24.66 \%$ of Hainan island. The center of this area is danzhou, which mainly develops high-quality coastal, industrial and historical and cultural tourism projects.

Sansha marine tourist area - this area includes Xisha, Nansha, zhongsha islands and the sea areas under its jurisdiction. Its development goal is to build the third largest marine tourism in the world, which will urge the region to give full play to the advantages of marine resources and protect the marine ecological environment. The functional zones include the Xisha islands marine tourism zone, the zhongsha islands marine tourism zone, and the Nansha islands cruise leisure tourism zone.

\subsubsection{The nine development groups}

The significance of tourism project groups lies in utilizing the convenient conditions of capital policies, developing cross-city and county cooperation, integrating adjacent tourism resources, and forming a regional tourism development pattern.

The nine tourism functional groups in Hainan involve the sea, rainforest, national culture, health care, science and technology, folk customs and many other aspects. Its function is to combine the tourism resources in the group reasonably and bring into full play the comprehensive benefits. In the future, tourism products within the group will be equipped with corresponding hardware facilities to meet the diversified needs of tourism consumers.

\section{Prospect}

Hainan has unique tourism resources, many of which are irreplaceable. At present, Hainan is facing a policy advantage - free trade zone. Therefore, the development prospect of Hainan tourism industry is very broad. With the support of the policy, Hainan's tourism consumption development space will be further expanded, the quality of tourism consumption service will be accelerated, and the internationalization of tourism consumption will be promoted rapidly. At the same time, how to combine high-quality tourism resources and advantageous policies in depth and maximize benefits is the direction that we need to work hard to develop.

\section{Acknowledgement}

This paper is supported by Construction of high quality vocational colleges in Hainan province. (Education of department of Hainan province)

\section{References}

[1] Wu yana. Analysis of spatial distribution characteristics of main tourism resources in Hainan province based on GIS [J]. Journal of Zhejiang Agricultural Sciences. 2017.05

[2] Zhoujinquan. Hainan tourism industry integration based on competitiveness promotion [J]. The New Orient. 2016.01 